\title{
Mass-Spectrometric Monitoring of the Thermally Induced Decomposition of Trimethylgallium, Tris(tert-Butyl)Gallium, and Triethylantimony at Low Pressure Conditions
}

\author{
Naoufal Bahlawane, Frank Reilmann, Linda-Christin Salameh, \\ and Katharina Kohse-Höinghaus \\ Department of Chemistry, Bielefeld University, Bielefeld, Germany
}

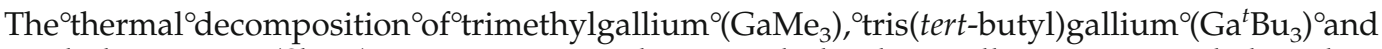
triethylantimony ${ }^{\circ}\left(\mathrm{SbEt}_{3}\right)^{\circ}$ was $^{\circ}$ investigated ${ }^{\circ}$ in $^{\circ} \mathrm{a}^{\circ}$ tubular $^{\circ}$ hot-wall $^{\circ}$ reactor $^{\circ}$ coupled $^{\circ}$ with $^{\circ}$ a molecular-beam ${ }^{\circ}$ sampling $^{\circ}$ mass $^{\circ}$ spectrometer $^{\circ}$ and $^{\circ}$ decomposition ${ }^{\circ}$ mechanisms $^{\circ}$ were ${ }^{\circ}$ proposed. The ${ }^{\circ}$ obtained ${ }^{\circ}$ esults ${ }^{\circ}$ confirm $^{\circ}$ the predominance $^{\circ}$ of the $^{\circ}$ surface ${ }^{\circ}$ reactions ${ }^{\circ}$ and ${ }^{\circ}$ reveal that the ${ }^{\circ}$ radical ${ }^{\circ}$ decomposition ${ }^{\circ}$ path $^{\circ}{ }^{\circ} f^{\circ} \mathrm{Ga}^{t} \mathrm{Bu}_{3^{\circ}}$ and ${ }^{\circ} \mathrm{SbEt}_{3},{ }^{\circ}$ responsible ${ }^{\circ}$ for ${ }^{\circ}$ the ${ }^{\circ}$ formation ${ }^{\circ}$ of ${ }^{\circ}$ butane and $^{\circ}$ ethane $^{\circ}$ respectively, ${ }^{\circ}$ is $^{\circ}$ restricted $^{\circ}$ to $^{\circ} \mathrm{a}^{\circ}$ narrow $^{\circ}$ temperature ${ }^{\circ}$ range $^{\circ}$ in $^{\circ}$ contrast $^{\circ}$ to ${ }^{\circ}$ the molecular ${ }^{\circ}$ route ${ }^{\circ}$ that $^{\circ}$ is $^{\circ}$ responsible ${ }^{\circ}$ for ${ }^{\circ}$ the ${ }^{\circ}$ formation ${ }^{\circ}$ of ${ }^{\circ}$ the ${ }^{\circ}$ corresponding $^{\circ}$ alkenes. ${ }^{\circ} \mathrm{GaMe}_{3}$ decomposes ${ }^{\circ}$ above $^{\circ} 480^{\circ} \mathrm{C}^{\circ},{ }^{\circ}$ forming ${ }^{\circ}$ essentially $^{\circ}$ methane ${ }^{\circ}$ and $^{\circ}$ also $^{\circ}$ ethane $^{\circ}$ to ${ }^{\circ} \mathrm{a}^{\circ}$ lesser ${ }^{\circ}$ extent, whereas ${ }^{\circ} \mathrm{Ga}^{t} \mathrm{Bu}_{3^{\circ}}$ decomposes ${ }^{\circ}$ starting ${ }^{\circ} 260^{\circ} \mathrm{C}^{\circ}$ to ${ }^{\circ}$ form ${ }^{\circ}$ predominantly ${ }^{\circ} i$-butane ${ }^{\circ}$ and $i$-butene ${ }^{\circ}$ as major ${ }^{\circ}$ species. ${ }^{\circ}{ }^{\circ}$ The ${ }^{\circ}$ decomposition ${ }^{\circ}$ of $^{\circ} \mathrm{SbEt}_{3^{\circ}}$ starts $^{\circ} \mathrm{at}^{\circ} 400^{\circ} \mathrm{C}^{\circ}$ and ${ }^{\circ}$ forms ${ }^{\circ} n$-butane, ${ }^{\circ}$ ethane, ${ }^{\circ}$ and ethene. ${ }^{\circ}$ The ${ }^{\circ}$ selectivity ${ }^{\circ}$ to $^{\circ} n$-butane ${ }^{\circ}$ increases ${ }^{\circ}$ with $^{\circ}$ the ${ }^{\circ}$ thermolysis ${ }^{\circ}$ temperature. ${ }^{\circ}$ The ${ }^{\circ}$ resulting activation ${ }^{\circ}$ energies $^{\circ}$ of ${ }^{\circ}$ the ${ }^{\circ}$ relevant ${ }^{\circ}$ decomposition $^{\circ}$ path $^{\circ}{ }^{\circ}$ show $^{\circ}$ good $^{\circ}$ agreement ${ }^{\circ}$ with $^{\circ}$ those among $^{\circ}$ them $^{\circ}$ that $^{\circ}$ have $^{\circ}$ been $^{\circ}$ measure $^{\circ}$ before $^{\circ}$ by $^{\circ}$ temperature-programmed ${ }^{\circ}$ desorption techniques. ${ }^{\circ}\left(\mathrm{J}^{\circ} \mathrm{Am}^{\circ}{ }^{\circ} \mathrm{Soc}^{\circ} \mathrm{Mass}^{\circ}{ }^{\circ} \text { Spectrom }{ }^{\circ} 2008,{ }^{\circ} 19,{ }^{\circ} 947-954\right)^{\circ}{ }^{\circ}{ }^{\circ} 2008^{\circ}$ American ${ }^{\circ}$ Society ${ }^{\circ}$ for ${ }^{\circ}$ Mass Spectrometry
\end{abstract}

\begin{abstract}
A ntimony-based ${ }^{\circ} I I I-V^{\circ}$ semiconductors ${ }^{\circ}$ receive $^{\circ}$ a widespread ${ }^{\circ}$ attention ${ }^{\circ}$ ecause $^{\circ}$ of ${ }^{\circ}$ their ${ }^{\circ}$ advantageous ${ }^{\circ}$ narrow-band ${ }^{\circ}$ gap $^{\circ}$ allowing ${ }^{\circ}$ the ${ }^{\circ}$ development $^{\circ}$ of $^{\circ}$ thermophotovoltaic ${ }^{\circ}$ devices ${ }^{\circ}\left[1,{ }^{\circ} 2\right],{ }^{\circ}$ the $e^{\circ}$ attainment $^{\circ}$ of $^{\circ}$ low $^{\circ}$ power $^{\circ}$ consumption $^{\circ}$ electronic $^{\circ}$ devices operating ${ }^{\circ}{ }^{\circ}{ }^{\circ}$ high-frequency ${ }^{\circ}[3],{ }^{\circ}{ }^{\circ} d^{\circ}$ of ${ }^{\circ}$ light-emitting diodes operating in ${ }^{\circ}$ the $1.6^{\circ}-4.4^{\circ} \mu \mathrm{m}$ 'spectral'range $[4]$. The $^{\circ}$ grow $^{\circ}{ }^{\circ}$ of $^{\circ}$ these ${ }^{\circ}$ materials ${ }^{\circ}$ starting ${ }^{\circ}$ from ${ }^{\circ}$ metalorganic ${ }^{0}$ recursors ${ }^{\circ}$ and ${ }^{\circ}$ sing $^{\circ}$ vapor-phase ${ }^{\circ}$ techniques such $^{\circ}$ as $^{\circ}$ molecular $^{\circ}$ beam $^{\circ}$ epitaxy $^{\circ}(\mathrm{MBE}),{ }^{\circ}$ chemical vapor ${ }^{\circ}$ deposition $(C V D),{ }^{\circ}$ and ${ }^{\circ}$ vapor-phase ${ }^{\circ}$ epitaxy ${ }^{\circ}$ are extensively ${ }^{\circ}$ investigated ${ }^{\circ}$ and $^{\circ}$ reported $^{\circ}$ in ${ }^{\circ}$ valuable reviews ${ }^{\circ}[5-7] .{ }^{\circ}$ For $^{\circ}$ the $^{\circ}$ growth $^{\circ}{ }^{\circ}{ }^{\circ}$ gallium ${ }^{\circ}$ antimonide, alkyl ${ }^{\circ}$ derivates ${ }^{\circ}$ are $^{\circ}$ widely $^{\circ}$ used $^{\circ}$ as $^{\circ}$ metal ${ }^{\circ}$ precursors. Therefore, ${ }^{\circ}$ the ${ }^{\circ}$ decomposition ${ }^{\circ}$ mechanism $^{\circ}$ of ${ }^{\circ}$ alkylgallium ${ }^{\circ}$ and $^{\circ}$ alkyl-antimony ${ }^{\circ}$ precursors $^{\circ}{ }^{\circ}{ }^{\circ} s^{\circ}{ }^{\circ}$ been ${ }^{\circ}$ investigated ${ }^{\circ}$ in $^{\circ}{ }^{\circ}$ etail $^{\circ}$ with $^{\circ}$ the ${ }^{\circ}$ objective ${ }^{\circ}$ of ${ }^{\circ}$ better $^{\circ}$ control $^{\circ}$ of $^{\circ}$ the $^{\circ}$ growth $^{\circ}$ process, ${ }^{\circ}$ analysis ${ }^{\circ}$ of ${ }^{\circ}$ potential sources ${ }^{\circ}$ of $^{\circ}$ contamination, $^{\circ}$ and ${ }^{\circ}$ determination ${ }^{\circ}$ of ${ }^{\circ}$ the kinetic ${ }^{\circ}$ parameters ${ }^{\circ}{ }^{\circ} f^{\circ}$ the ${ }^{\circ}$ rate-limiting ${ }^{\circ}$ reactions..$^{\circ}$ For this ${ }^{\circ}$ purpose, ${ }^{\circ}$ temperature-programmed ${ }^{\circ}$ desorption (TPD) ${ }^{\circ}$ is ${ }^{\circ}$ by $^{\circ}$ far $^{\circ}$ the ${ }^{\circ}$ most $^{\circ}$ frequently ${ }^{\circ}$ used $^{\circ}$ technique [8-17]..$^{\circ}$ This ${ }^{\circ}$ technique, ${ }^{\circ}$ which ${ }^{\circ}$ relies ${ }^{\circ}{ }^{\circ}{ }^{\circ}$ low-temperature
\end{abstract}

Address reprint requests to Dr. N. Bahlawane, Department of Chemistry, Bielefeld University, Universitätsstr. 25, 33615 Bielefeld, Germany. E-mail: naoufal@pc1.uni-bielefeld.de adsorption ${ }^{\circ}$ followed ${ }^{\circ}$ by $^{\circ}$ the ${ }^{\circ}$ thermal ${ }^{\circ}$ activation $^{\circ}$ of ${ }^{\circ}$ the surface $^{\circ}$ reactions ${ }^{\circ}$ in $^{\circ}$ ultra-high $^{\circ}$ vacuum ${ }^{\circ}$ operates $^{\circ}$ under highly ${ }^{\circ}$ irreversible ${ }^{\circ}$ conditions $^{\circ}$ and ${ }^{\circ}$ involves ${ }^{\circ}$ exclusively surface ${ }^{\circ}$ reactions. ${ }^{\circ}$ However, ${ }^{\circ}$ these ${ }^{\circ}$ conditions ${ }^{\circ}$ diverge from ${ }^{\circ}$ the ${ }^{\circ}$ deposition ${ }^{\circ}$ conditions $^{\circ}$ that ${ }^{\circ}$ involve ${ }^{\circ}$ adsorption at ${ }^{\circ}$ high ${ }^{\circ}$ temperature, ${ }^{\circ}$ which $^{\circ}$ might $^{\circ}$ result ${ }^{\circ}{ }^{\circ}{ }^{\circ} a^{\circ}$ different product ${ }^{\circ}$ distribution, ${ }^{\text {maybe }}{ }^{\circ}$ even including the appearance ${ }^{\circ}{ }^{\circ}{ }^{\circ} w^{\circ}$ products $^{\circ}[18] .{ }^{\circ}$ Furthermore, ${ }^{\circ}$ the ${ }^{\circ}$ deposition conditions ${ }^{\circ}$ in $^{\circ} \mathrm{CVD}^{\circ}$ and ${ }^{\circ} \mathrm{MBE}^{\circ}$ operate ${ }^{\circ}$ under ${ }^{\circ}$ steady ${ }^{\circ}$ flow of $^{\circ}$ the ${ }^{\circ}$ precursor, ${ }^{\circ}$ which ${ }^{\circ}$ contrasts $^{\circ}$ with $^{\circ}$ the ${ }^{\circ}$ adsorbate depletion ${ }^{\circ}$ that ${ }^{\circ}$ is ${ }^{\circ}$ an ${ }^{\circ}$ inherent ${ }^{\circ}$ disadvantage $^{\circ}$ of ${ }^{\circ}$ the $e^{\circ} \mathrm{TPD}$ technique.

The in ${ }^{\circ}$ situ $^{\circ}$ mass $^{\circ}$ spectrometric $^{\circ}$ analysis ${ }^{\circ}$ of ${ }^{\circ}$ sampled gas 9 from the ${ }^{\circ}$ deposition reactor $[19,20]^{\circ}$ and ${ }^{\circ}$ molecular beam $^{\circ}$ scattering $^{\circ}[21]^{\circ}$ might $^{\circ}$ overcome ${ }^{\circ}$ the ${ }^{\circ}$ abovementioned ${ }^{\circ}$ difficulties. ${ }^{\circ}$ Nevertheless, ${ }^{\circ}$ this ${ }^{\circ}$ technique was ${ }^{\circ}$ infrequently ${ }^{\circ}$ used, ${ }^{\circ}$ and ${ }^{\circ}$ has $^{\circ}$ been $^{\circ}$ limited $^{\circ}$ to $^{\circ}$ the identification ${ }^{\circ}$ of $^{\circ}$ the $e^{\circ}$ occurring $^{\circ}$ reactions.

In $^{\circ}$ this ${ }^{\circ}$ study, ${ }^{\circ}$ molecular ${ }^{\circ}$ beam $^{\circ}$ sampling ${ }^{\circ}$ mass spectrometry ${ }^{\circ}$ was $^{\circ}$ used $^{\circ}$ for $^{\circ}$ the ${ }^{\circ}$ investigation ${ }^{\circ}$ of ${ }^{\circ}$ the thermolysis of relevant gallium and antimony precursors under steady flow near-deposition conditions, with the objective to identify the reaction pathways, potentially including some that have not been detected by the TPD technique, to understand their importance and to determine the corresponding kinetic parameters. 


\section{Experimental}

The thermolysis reaction was investigated in a stainless steel tubular hot-wall reactor at low pressure, while the precursor was delivered from an evaporator maintained at constant temperature using argon carrier gas with a flow rate of $5 \mathrm{sccm}$. The evaporation of $\mathrm{GaMe}_{3}$, $\mathrm{Ga}^{t} \mathrm{Bu}_{3}$, and $\mathrm{SbEt}_{3}$ was performed at 0,12 , and $25^{\circ} \mathrm{C}$, respectively. The tubular reactor has an i.d. of $8 \mathrm{~mm}$ and a length of $600 \mathrm{~mm}$, offering a high surface-to-volume ratio $\left(\mathrm{S} / \mathrm{V}=0.5 \mathrm{~mm}^{-1}\right)$, which is favorable to emphasize the surface gas interactions. Nevertheless, this configuration imposes a pressure gradient along the reactor. A pressure of $10^{-3}$ mbar was measured at the inlet part of the reactor, while $1.5-7 \times 10^{-5}$ mbar was attained at the outlet where the gas sampling is preformed. The residence time of the gaseous molecules in the tubular reactor was estimated to be 14,5 , and $25 \mu \mathrm{s}$ for $\mathrm{GaMe}_{3}, \mathrm{Ga}^{t} \mathrm{Bu}_{3}$ and $\mathrm{SbEt}_{3}$, respectively, considering the pressure measured in the outlet part of the reactor. Due to routinely performed adjustments and the preliminary preparation at high temperature prior each test, the walls are assumed to be coated with Ga when $\mathrm{GaMe}_{3}$, and $\mathrm{Ga}^{t} \mathrm{Bu}_{3}$ were investigated and with Sb film when $\mathrm{SbEt}_{3}$ was investigated. A copper skimmer was used to extract a gas sample from the pyrolysis reactor to the ionization chamber, which is pumped down to $<5 \times 10^{-6}$ mbar. The sampled gas is then subjected to electron-impact ionization before analysis with a timeof-flight mass spectrometer (Kaesdorf), equipped with a reflectron. The mass resolution of this instrument is $\mathrm{m} / \Delta \mathrm{m}=4000$. The energy of the electron beam is tunable between 5 and $40 \mathrm{eV}$, and analysis with 10 and $20 \mathrm{eV}$ was routinely used to minimize electronic fragmentation and to allow its discrimination from the thermally induced reactions.

\section{Results and Discussion}

\section{Trimethylgallium}

The thermolysis of $\mathrm{GaMe}_{3}$ was investigated at temperatures between 100 and $570{ }^{\circ} \mathrm{C}$, while the ionization was performed with an average energy of $10 \mathrm{eV}$. Nevertheless, the energy distribution of the electron beam presents a high-energy tail. The small fraction of energetic electrons induces a non-negligible fragmentation. The registered spectra show a small argon signal, indicating the presence of electrons with an energy that slightly surpasses $15.8 \mathrm{eV}$. The electronic fragmentation of $\mathrm{GaMe}_{3}$ is evident in Figure 1 at the reactor temperature of $70{ }^{\circ} \mathrm{C}$, where several gallium-containing fragment ions can be observed. Increasing the reactor temperature to $570{ }^{\circ} \mathrm{C}$ leads to a complete depletion of these species and to the formation of methane as the major product and of small amount of ethyne and ethane. No species with masses above that of $\mathrm{GaMe}_{3}$ were detected, which indicates the presence of the precursor in the gas phase as monomer.

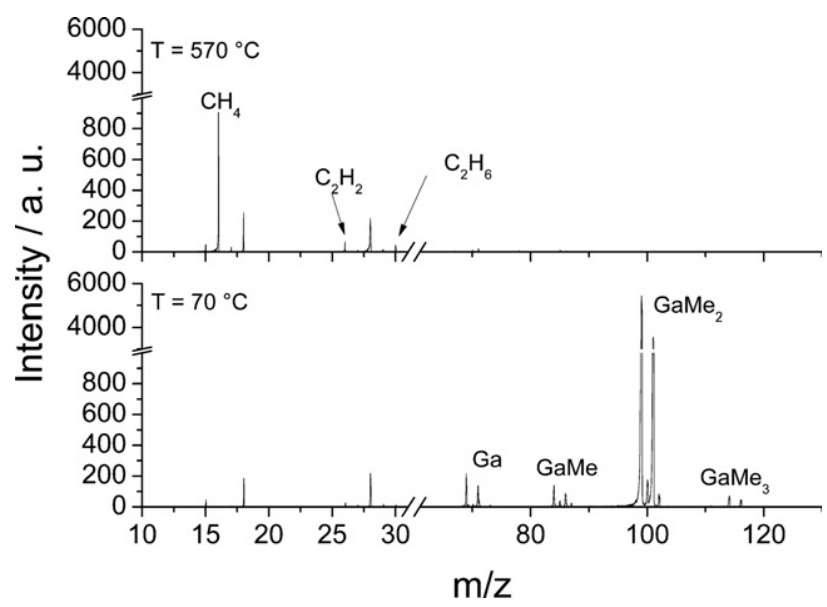

Figure 1. Mass spectra of $\mathrm{GaMe}_{3}, \mathrm{CVD}$ reactor at $570{ }^{\circ} \mathrm{C}$ and $70{ }^{\circ} \mathrm{C}$.

Figure 2 shows the effect of the thermolysis temperature on the intensity of the gallium-containing fragment ions, which exhibit a single trend. This is an indication of their provenance from the electronic fragmentation rather than from the thermolysis reaction. The apparent absence of gallium-containing thermolysis intermediates indicates either their extremely low concentration or their trapping, eventually at the surface, which hints at the dominant role of the heterogeneous route in the thermolysis reaction of $\mathrm{GaMe}_{3}$. The presence of ammonia was reported to induce gas-phase reactions at significantly low temperatures [22-24] to form higher mass Lewis-acid-base adducts. Schafer et al. [22] indicate that even in the presence of ammonia, the homogeneous thermal decomposition of $\mathrm{GaMe}_{3}$ to $\mathrm{GaMe}_{2}, \mathrm{GaMe}$ and Ga are only observed above $700{ }^{\circ} \mathrm{C}$, which agrees with the results obtained here. Therefore, it is reasonable to attribute the observed behavior below $600{ }^{\circ} \mathrm{C}$ to the occurring heterogeneous reactions. In this study, as seen in Figure 2, $\mathrm{GaMe}_{3}$ exhibits a good thermal stability up to $480^{\circ} \mathrm{C}$, even in a reactor with high surface-to-volume ratio. Above this temperature, the molecular peak intensity decays abruptly and no precursor can be detected at $570{ }^{\circ} \mathrm{C}$.

Assuming a first-order kinetics and an estimated pre-exponential factor of $\mathrm{A}=10^{13} \mathrm{~s}^{-1}$, this observed decay of the precursor intensity and the increase of the intensities of methane and ethane (Figure 2) would deliver activation energies of 202, 189, and $203 \mathrm{~kJ} / \mathrm{mol}$, respectively. These values are close to the calculated $184-192 \mathrm{~kJ} / \mathrm{mol}$ by Creighton et al. [8], $180 \mathrm{~kJ} / \mathrm{mol}$ by McCaulley et al. [9], $195 \mathrm{~kJ} / \mathrm{mol}$ by Wong et al. [10], and largely diverge from the computed activation energy in the gas phase $(>300 \mathrm{~kJ} / \mathrm{mol})[25,26]$. The experimentally measured activation energy of the homogeneous reaction by Jacko and Price [27] $(249 \mathrm{~kJ} / \mathrm{mol})$ and by Chen and Dapkus [19] $(270 \mathrm{~kJ} / \mathrm{mol})$ are likely to be affected by the surface catalytic effect [25]. This low registered value in this work diverges significantly from the high activation energy of the homogeneous 

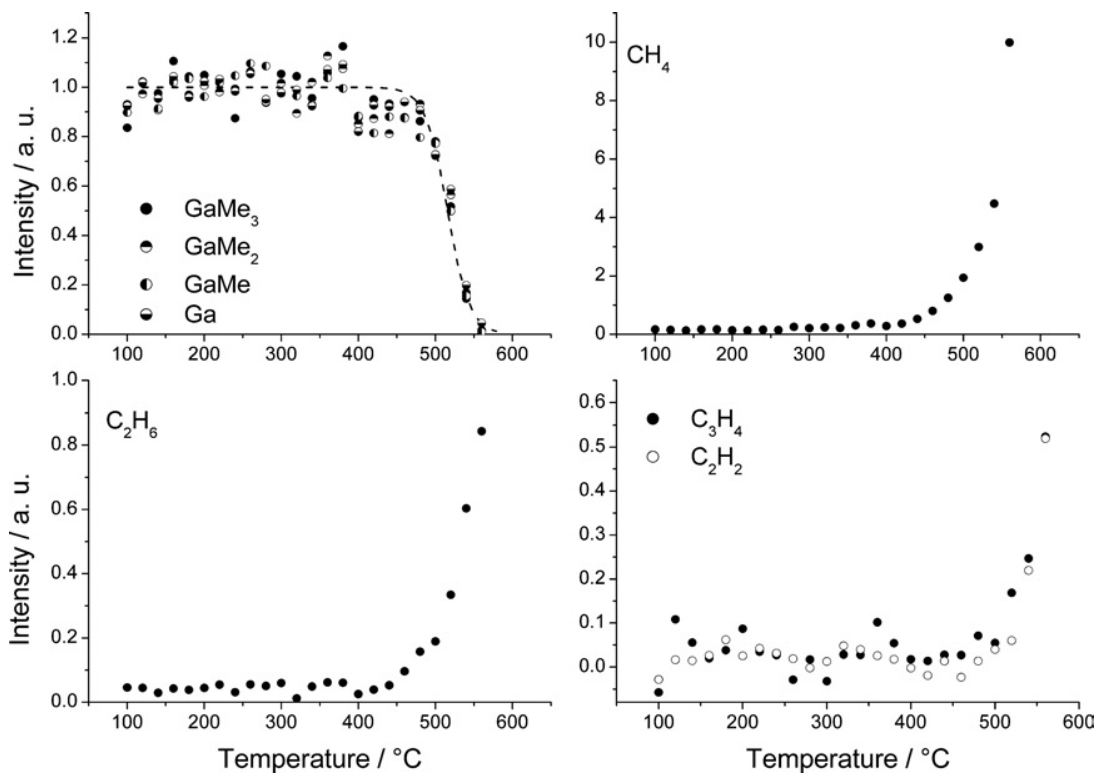

Figure 2. Temperature-dependent intensity of $\mathrm{GaMe}_{3}$ and the products of its thermolysis.

reaction and fits well to values measured with techniques involving exclusively the surface decomposition process [8-10], which confirms that the heterogeneous reactions dominate.

The thermal decomposition of $\mathrm{GaMe}_{3}$ on well-defined surfaces ( $\mathrm{Si}$ and GaAs) has been intensively investigated earlier using a variety of surface-sensitive techniques [8-14]. It is generally agreed that $\mathrm{GaMe}_{3}$ adsorbs dissociatively at room temperature or even at lower temperatures and undergoes stepwise loss of methyl groups with increased temperature to form surface methyl species.

On silicon substrates [11], surface heating leads to the depletion of $\mathrm{Si}-\mathrm{CH}_{3}$ surface groups at $430^{\circ} \mathrm{C}$ to form $\mathrm{Si}-\mathrm{H}$ species with maximal intensity at $450-480{ }^{\circ} \mathrm{C}$. The remaining carbon is indicated to be the cause of the films' contamination during the deposition starting from $\mathrm{GaMe}_{3}$. The decomposition is completed when hydrogen is desorbed at $480-580{ }^{\circ} \mathrm{C}$.

On GaAs substrates, Aquino and Jones [12] demonstrated that methyl $\left(\mathrm{CH}_{3}\right)$ groups undergo hydrogen abstraction even at temperatures as low as $200{ }^{\circ} \mathrm{C}$, but this reaction is most enhanced at $400{ }^{\circ} \mathrm{C}$. As a product of this reaction, surface methylene $\left(\mathrm{CH}_{2}\right)$ groups are formed. A complete decomposition of adsorbed species is only reached at $500{ }^{\circ} \mathrm{C}$. Based on these reports [11, 12], it can be concluded that a significant deposition using $\mathrm{GaMe}_{3}$ will not be expected below $480{ }^{\circ} \mathrm{C}$ because of the surface saturation with adsorbed species [8]. This agrees with the $\mathrm{GaMe}_{3}$ depletion curve in Figure 2 that starts above $480^{\circ} \mathrm{C}$.

The heterogeneous thermolysis of $\mathrm{GaMe}_{3}$ was reported to form a metallic gallium core with a carbon shell [28]. This agrees with the TPD study performed by Flores et al. [11], which shows the desorption of hydrogen, but no carbon-containing species at high tempera- ture. In contrast, other studies report the desorption of $\mathrm{CH}_{3}$ at high temperature and at low surface coverage [8, $9,13]$, while ethane [14], methane [13], or a mixture of methane and ethane [19] desorb at high surface coverage.

In the current investigation, which is characterized by a continuous flow of the precursor $\mathrm{GaMe}_{3}$, several hydrocarbons were produced with increased temperature as shown in Figure 2. The most abundant product in our case is methane, even if no additional hydrogen was used. This indicates the occurrence of the hydrogen abstraction reaction between two adjacent surface methyl groups. The second abundant species in terms of signal intensity is ethane, which presumably results from the recombination of two surface methyl groups. The formation of methane and ethene as a result of the gas-phase reaction of methyl radical with the $\mathrm{GaMe}_{3}$ was ruled out since the thermal production of galliumcontaining intermediates was not confirmed. In addition to methane and ethane, other hydrocarbons were produced to a lesser extent. The detection of ethyne and $\mathrm{C}_{3} \mathrm{H}_{4}$ is an evidence of the occurrence of significant surface recombination of methyl groups to form larger hydrocarbons. The formation of unsaturated hydrocarbons is not favorable for the growth of carbon-free gallium films. An overview of the suggested thermolysis reaction mechanism is depicted in Scheme $\mathbf{1}$.

\section{Tris(tert-butyl)gallium}

The second investigated gallium precursor is $\mathrm{Ga}^{t} \mathrm{Bu}_{3}$, which was shown to exhibit a monomeric molecular structure [29]. This precursor presents a particular relevance since the $\mathrm{Ga}-{ }^{t} \mathrm{Bu}$ group is frequently considered as part of III-V single source precursors [15, 30-32]. The thermolysis of this precursor was investigated between 30 and $600{ }^{\circ} \mathrm{C}$. The mass spectrum of the sampled gas 


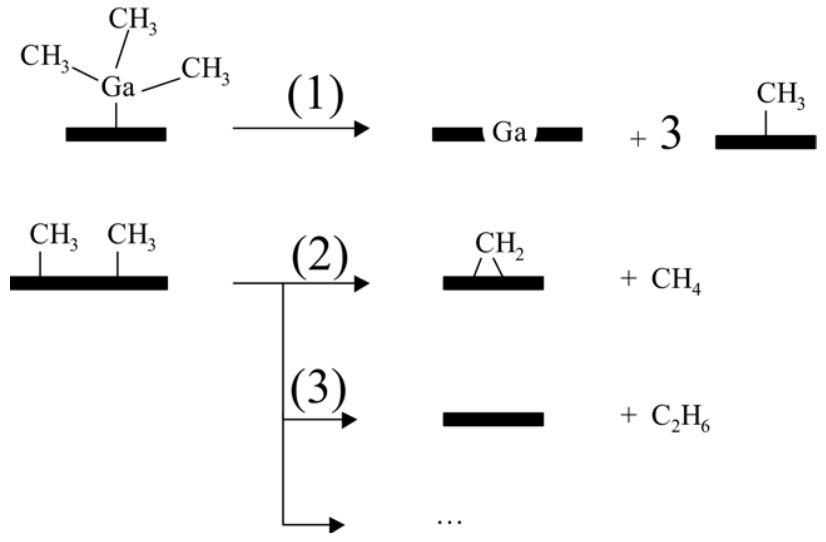

Scheme 1. Schematic presentation of the proposed thermolysis reaction of $\mathrm{GaMe}_{3}$. Reaction (1) represents the methyl ligand transfer to the surface, while (2) and (3), respectively, show hydrogen abstraction and recombinative desorption of two adjacent surface methyl groups.

from the reactor at $30^{\circ} \mathrm{C}$, available as Supplementary Materials (which can be found in the electronic version of this article), shows the presence of the molecular peak as well as signals corresponding to a stepwise abstraction of ${ }^{t} \mathrm{Bu}$ ligands upon electron ionization. In addition to gallium-containing fragment ions, this spectrum shows also the presence of $\mathrm{C}_{4}{ }^{-}$and $\mathrm{C}_{3}$-species that are also the result of the electronic fragmentation of the precursor. At high temperature, the intensity of galliumcontaining fragment ions completely vanished, and $\mathrm{C}_{4}{ }^{-}$ and $\mathrm{C}_{3}$-fragment ions are strengthened, indicating the completed decomposition of the precursor.

The evolution of gallium-containing fragment ions as a function of the reactor temperature is presented in Figure 3. Clearly, all these fragment ions present a single fit, which indicates their provenance from the same molecule, through the electronic fragmentation, in the entire investigated temperature range. Referring to the detected signals, it is concluded that no detectable gas-phase gallium-containing intermediates are formed by the thermolysis of $\mathrm{Ga}^{t} \mathrm{Bu}_{3}$. Trends in Figure 3 indicate that the decomposition of $\mathrm{Ga}^{t} \mathrm{Bu}_{3}$ starts at $260^{\circ} \mathrm{C}$ and is terminated at $370{ }^{\circ} \mathrm{C}$, which is more than $200^{\circ} \mathrm{C}$ lower than for $\mathrm{GaMe}_{3}$.

The major product of the decomposition of $\mathrm{Ga}^{t} \mathrm{Bu}_{3}$ is $\mathrm{C}_{4} \mathrm{H}_{8}$ (i-butene) as indicated in Figure 3. $i$-Butene is mainly detected in its molecular state but also as weak signals from $\mathrm{C}_{2} \mathrm{H}_{4}^{+}, \mathrm{C}_{3} \mathrm{H}_{5}^{+}, \mathrm{C}_{4} \mathrm{H}_{6}^{+}$, and $\mathrm{C}_{4} \mathrm{H}_{7}^{+}$, due to the electronic fragmentation. The non-zero intensity below $200^{\circ} \mathrm{C}$ can be attributed to the electronic fragmentation of the precursor molecule, which produces mainly $\mathrm{C}_{4} \mathrm{H}_{9}^{+}$but also signals of $\mathrm{C}_{2} \mathrm{H}_{8}^{+}$and $\mathrm{C}_{4} \mathrm{H}_{10}^{+}$. The production of $i$-butene is observed in early work for a number of simple tert-butyl compounds (chloride, bromide, and mercaptan) [33], and also in arsenic compounds containing ${ }^{t} \mathrm{Bu}$ ligands [34]. Similar to the photolysis reaction [35], the production of $i$-butene from the thermal decomposition of $\mathrm{Ga}^{t} \mathrm{Bu}_{3}$ indicates the occurrence of the $\beta$-hydride elimination reaction. The detection of hydrogen starting a temperature of $260{ }^{\circ} \mathrm{C}$ indicates the recombinative desorption of surface hydrogen issued from the $\beta$-hydride elimination reaction.

The activation energy was calculated to be $145 \mathrm{~kJ} /$ $\mathrm{mol}$ and $142 \mathrm{~kJ} / \mathrm{mol}$ from the trends of the precursor molecular peak and of the produced $i$-butene respectively, assuming a first-order reaction kinetics and a pre-exponential factor of $\mathrm{A}=10^{13} \mathrm{~s}^{-1}$. Both values are almost equal, which indicates that the $\beta$-hydride elimination is the rate-limiting step in the consumption of the precursor. Wong et al. [10] have calculated an activation energy of $145 \mathrm{~kJ} / \mathrm{mol}$, also assuming a preexponential factor of $\mathrm{A}=10^{13} \mathrm{~s}^{-1}$ using TPD, where
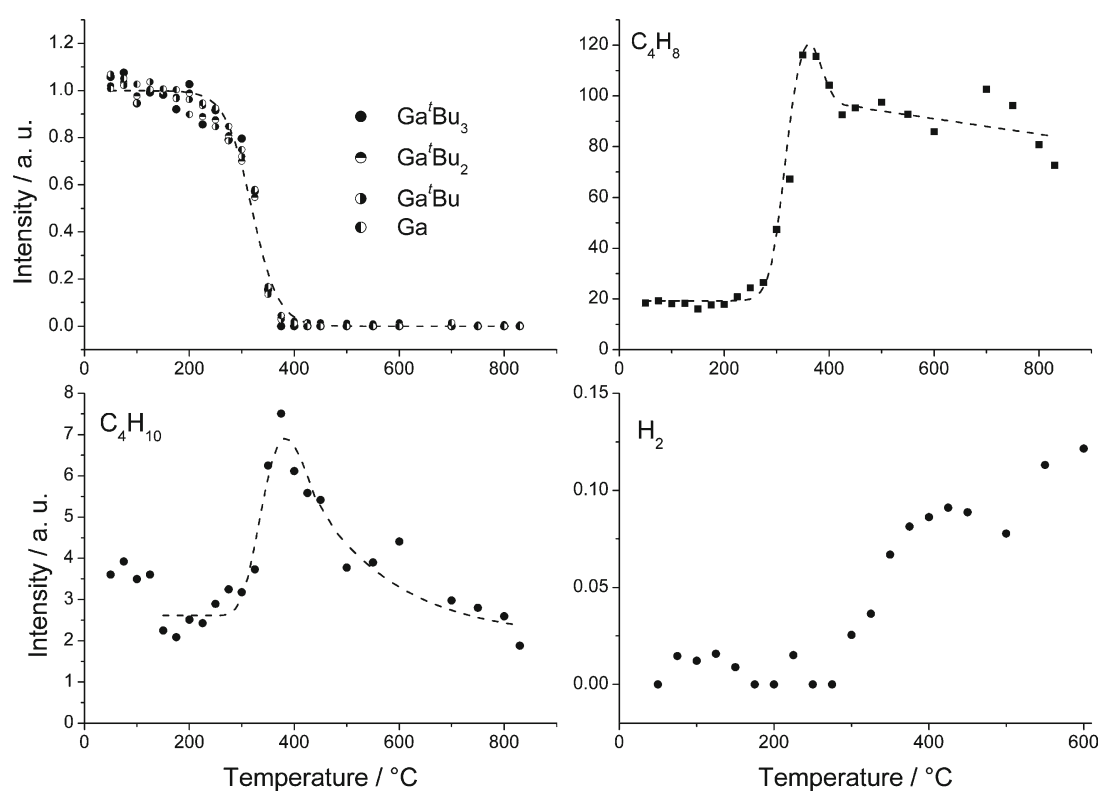

Figure 3. Temperature-dependent intensity of $\mathrm{Ga}^{t} \mathrm{Bu}_{3}$ and the products of its thermolysis. 
only surface reactions are considered. These values are slightly lower than the computed value of 157 $\mathrm{kJ} / \mathrm{mol}$ by Boero et al. for the $\beta$-hydride elimination reaction [36].

As a minor $\mathrm{C}_{4}$-species, the mass spectrometry investigation indicates the presence of $\mathrm{C}_{4} \mathrm{H}_{10}$ ( $i$-butane), see Figure 3, with a maximum intensity at $380^{\circ} \mathrm{C}$. The electronic fragmentation of this species is assumed to be responsible for the spike observed in the profile of $\mathrm{C}_{4} \mathrm{H}_{8}$.

The production of $i$-butane was also observed by Hopcus et al. [30] during the heterogeneous thermolysis of the single-source precursor $\left[{ }^{t} \mathrm{BuGaS}\right]_{4}$ at high surface coverage, and was considered to hint at the occurrence of a competing decomposition pathway. The production of $i$-butane in addition to $i$-butene was also observed during the thermolysis of $\mathrm{Se}^{t} \mathrm{Bu}_{2}$ [37]. These authors assumed the occurrence of a homolytic cleavage of the Se-C [37] or Ga-C [30] bonds, producing ${ }^{t} \mathrm{Bu}$ radical that initiates a surface or gas-phase chain reaction. The trend exhibited by $i$-butane, Figure 3 , indicates that the assumed homolytic cleavage reaction is favored in a narrow temperature range $\left(300-500^{\circ} \mathrm{C}\right)$. The overall deposition mechanism is schematically depicted in Scheme 2.

\section{Triethylantimony}

The investigation of the thermolysis of $\mathrm{SbEt}_{3}$ was performed between room temperature and $650{ }^{\circ} \mathrm{C}$. As for the gallium precursors, the electronic ionization induces significant fragmentation. Although the highest intensity is exhibited by the parent peak at the ionization energy of $10 \mathrm{eV}, \mathrm{SbEt}_{3}$ is also detected with the loss of one or two ethyl ligands. The intensity of these peaks upon thermolysis follows an identical trend as shown in Figure 4, which indicates their provenance from the electronic fragmentation of the molecular precursor. Since these three species are the only detected antimonycontaining fragment ions, it is concluded that the thermolysis process does not lead to the formation of gas-phase antimony-containing intermediates, which hints at their surface trapping.

The trend of the intensity of $\mathrm{SbEt}_{3}$ (Figure 4) was unaltered below $400{ }^{\circ} \mathrm{C}$, which indicates the stability of the precursor in the gas phase. This observation is in agreement with an early investigation [16], which demonstrates that $\mathrm{SbEt}_{3}$ undergoes dissociative adsorption on GaAs surfaces at temperatures as low as $50{ }^{\circ} \mathrm{C}$, however, this process is self-limited even at $400{ }^{\circ} \mathrm{C}$. Assumed that $\mathrm{SbEt}_{3}$ also adsorbs dissociatively on the surface of walls of the reactor that have been coated with antimony during the process, the constant intensity of the molecular peak would be an indication that the surface is saturated with adsorbed antimony species. A decay of the signal intensity starts at $400^{\circ} \mathrm{C}$, indicating the non-selflimited growth above $400{ }^{\circ} \mathrm{C}$, and the precursor was completely depleted above $550{ }^{\circ} \mathrm{C}$. The complete consumption of the precursor indicates

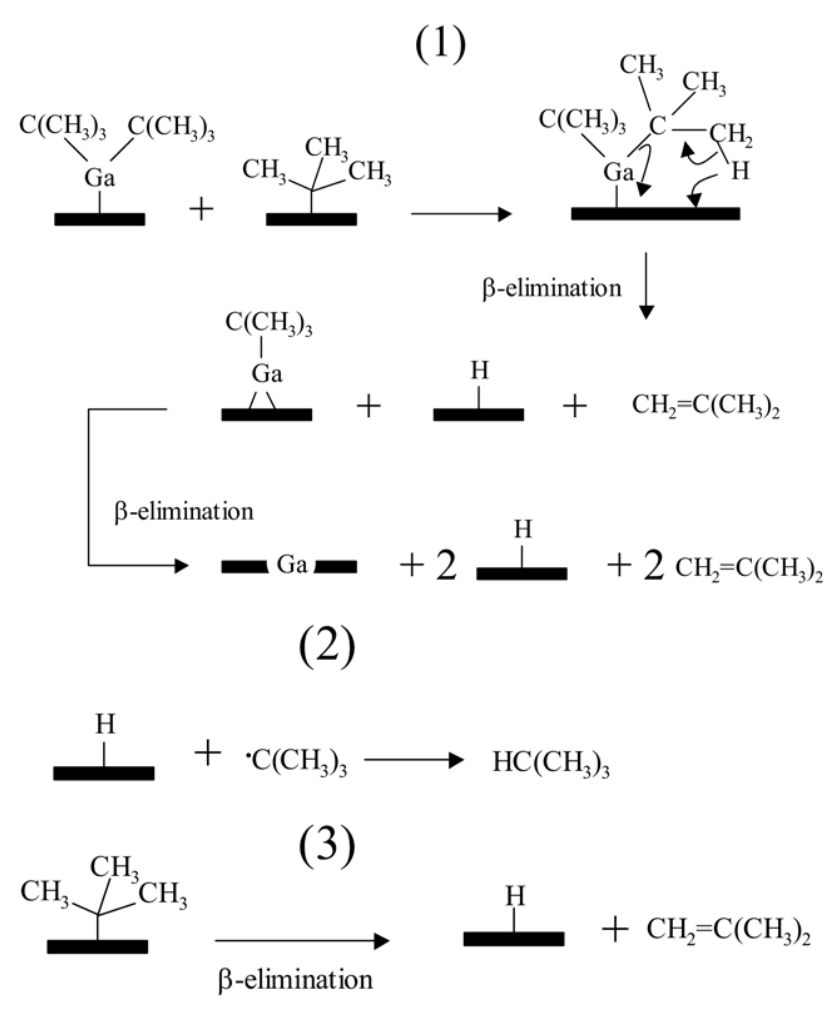

(4)

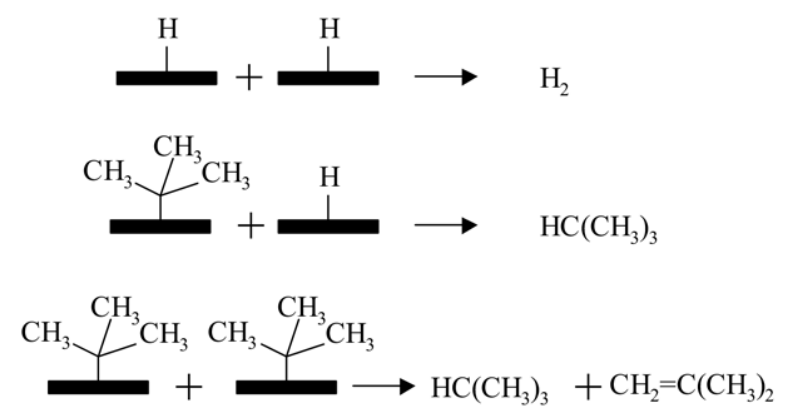

Scheme 2. Schematic representation of the proposed thermolysis reaction of $\mathrm{Ga}^{t} \mathrm{Bu}_{3}$. Reaction (1) presents the stepwise loss of tert-butyl groups via $\beta$-hydride elimination to yield gas-phase $i$-butene and surface hydrogen and gallium deposit. Step (2) shows the reaction of tert-butyl radical and surface hydrogen to form $i$-butane. The tert-butyl radical is the result of a homolytic cleavage of the $\mathrm{Ga}-\mathrm{C}$ bonds of adsorbed $\mathrm{Ga}^{i} \mathrm{Bu}_{2}$ or gas-phase precursor. Step (3) represents the $\beta$-hydride elimination of the surface $t$-butyl group to form desorbed $i$-butene and surface hydrogen. Reactions (4) correspond to the surface recombinations that form molecular hydrogen and $i$-butane, and disproportionation reaction forming $i$-butane and $i$-butene.

that the rate of the surface decomposition surpasses the feeding rate.

At $650{ }^{\circ} \mathrm{C}$, where the complete decomposition of the precursor is achieved, gas-phase analysis indicates the presence of low-mass peaks. Spectra of the expected species were recorded under similar ionization conditions to facilitate the access to the composition of the exhaust gas. Mass spectra, available as Supplementary Materials, show that ethene and $n$-butane are the main 

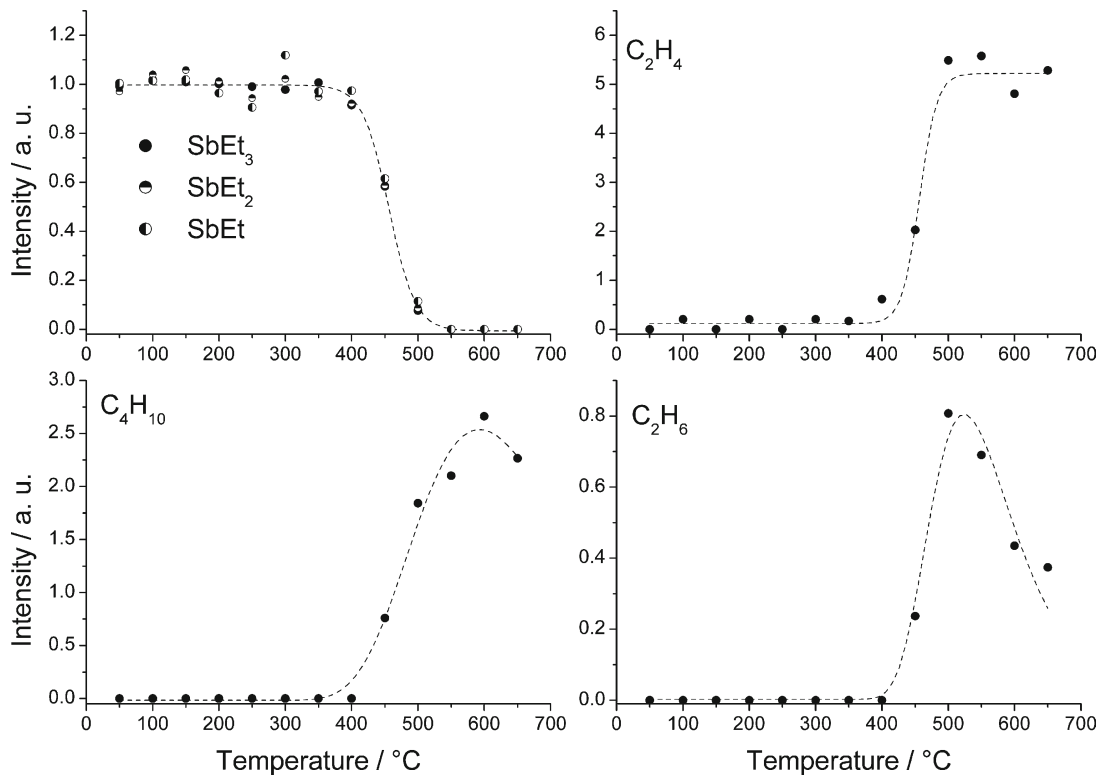

Figure 4. Temperature-dependent intensity of $\mathrm{SbEt}_{3}$ and the product if its thermolysis.

products of the precursor thermolysis. A semiquantitative interpretation, based on the signals intensity, shows that the reaction path leading to the formation of $n$-butane is more favorable at high temperature. The thermolysis products, ethene and $n$-butane, are detected above $400{ }^{\circ} \mathrm{C}$ and show a plateau near $500{ }^{\circ} \mathrm{C}$ where the precursor is almost depleted. As a minor species, the mass spectra reveal the presence of ethane that shows a maximal intensity at $500{ }^{\circ} \mathrm{C}$. The depicted results in Figure 4 indicate the occurrence of at least three reaction paths.

It is concluded from these observations that the $\mathrm{SbEt}_{3}$ molecule adsorbs dissociatively on the hot surface by the loss of an ethyl ligand. Further stepwise loss of ethyl ligands leads to the formation of atomic surface antimony and surface ethyl groups, in accord with a behavior observed on GaAs surface by Heitzinger et al. [16] using X-photoelectron spectroscopy. The decay of the intensity of $\mathrm{SbEt}_{3}$ was exploited assuming firstorder reaction kinetics and a pre-exponential factor of $10^{13} \mathrm{~s}^{-1}$. The activation energy of the decomposition of $\mathrm{SbEt}_{3}$ was calculated to be $183 \mathrm{~kJ} / \mathrm{mol}$, which is significantly lower than the $\mathrm{Sb}-\mathrm{C}$ bond strength $(240 \mathrm{~kJ} / \mathrm{mol})$ [38] in $\mathrm{SbEt}_{3}$. As for $\mathrm{GaMe}_{3}$, this observation agrees with the surface stabilization of the decomposition intermediates. The dissociative adsorption of the precursor forms surface ethyl groups that are expected to desorb either as ethyl radical or as ethane after reaction with surface hydrogen. In this investigation, ethane was observed as a minor product of thermolysis, Figure 4, starting at a temperature of $400{ }^{\circ} \mathrm{C}$. The trend of its production reveals an activation energy of $191 \mathrm{~kJ} / \mathrm{mol}$ $\left(\mathrm{A}=10^{13} \mathrm{~s}^{-1}\right)$, which is close to that calculated from the depletion of the precursor $(183 \mathrm{~kJ} / \mathrm{mol})$.

Two adjacent surface ethyl groups might undergo recombination to form $n$-butane or a disproportionation reaction to form ethane and ethene. These paths are seen to be dominating in the present case, which indicates the high surface coverage. The recombinative desorption, which was reported for the thermolysis of $\mathrm{GaMe}_{3}[14,35]$ and $\mathrm{Se}^{t} \mathrm{Bu}_{2}$ [37], is observed here for the first time during the thermolysis of $\mathrm{SbEt}_{3}$. This reaction increasingly dominates with increased temperature and forms $n$-butane with an activation energy of $161 \mathrm{~kJ} / \mathrm{mol}$ $\left(\mathrm{A}=10^{13} \mathrm{~s}^{-1}\right)$.

Isolated surface ethyl groups might undergo $\beta$ hydride elimination to form surface hydrogen and desorbed ethene with an activation energy of $149 \mathrm{~kJ} /$ mol $\left(\mathrm{A}=10^{13} \mathrm{~s}^{-1}\right)$. The occurrence of $\beta$-hydride elimination was reported as the dominant path for the decomposition of $\mathrm{SbEt}_{3}$ in TPD conditions [16, 17]. The analysis of the TPD of ethene, as a consequence of the thermal decomposition of $\mathrm{SbEt}_{3}$ on $\mathrm{GaAs}$ surface, indicates an activation energy of $146 \mathrm{~kJ} / \mathrm{mol}(\mathrm{A}=$ $10^{13} \mathrm{~s}^{-1}$ ) [16] that is in good agreement with the calculated value from the mass spectrometric analysis (149 $\mathrm{kJ} / \mathrm{mol}$ ).

Since no hydrogen was formed during the thermolysis of $\mathrm{SbEt}_{3}$ in our case, the reaction of the surface hydrogen with ethyl group to form ethane is assumed and supported by the ethane signal that shows a maximum at $500{ }^{\circ} \mathrm{C}$ as depicted in Figure 4 . The thermolysis of triethylantimony shows a clean decomposition path, where the molecule adsorbs dissociatively by the transfer of its ligands to the surface. Mass spectrometric analysis shows surprisingly that the dominant paths include the recombination of ethyl groups to form $n$-butane, which contrast with TPD studies where only the $\beta$-hydride elimination dominates [16, 17]. The substantial detection of ethene indicates the occurrence of $\beta$-hydride elimination or a disproportionation reaction. The last reaction is supported by the detection of small 


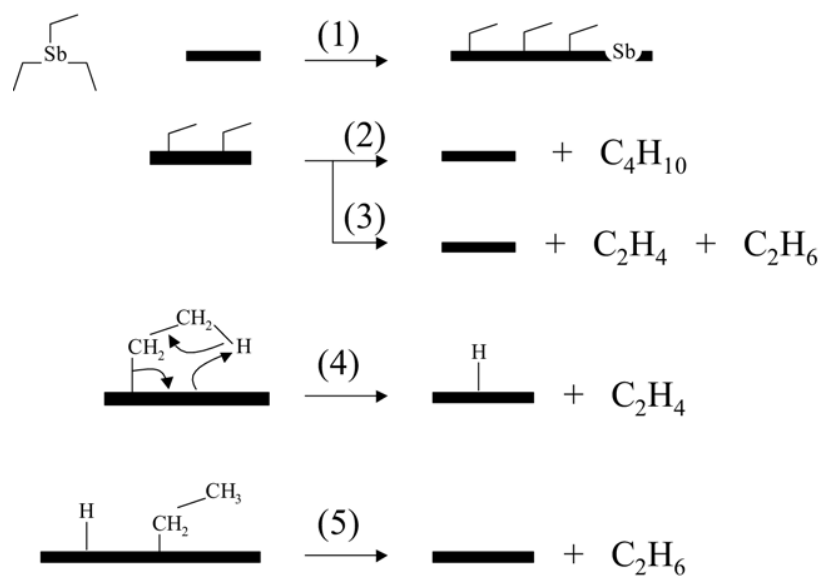

Scheme 3. Schematic representation of the proposed thermolysis reaction of $\mathrm{SbEt}_{3}$. Reaction (1) corresponds to the stepwise migration of ethyl ligands from the $\mathrm{SbEt}_{3}$ molecule to the surface. Reaction (2) shows the recombination of two ethyl radicals to form $n$-butane, while (3) shows disproportionation to form desorbed ethene and ethane. $\beta$-Hydride elimination leads to the desorption of ethene (4) and the formation of surface hydrogen that can recombine with an adjacent ethyl group to desorb as ethane molecule (5).

amounts of ethane. A schematic overview of the proposed mechanism for the decomposition of $\mathrm{SbEt}_{3}$ is represented in Scheme 3.

\section{Conclusions}

The thermal decomposition of three CVD precursors was investigated using molecular-beam mass spectrometry, which is coupled with a hot-wall tubular reactor with high surface-to-volume ratio. This configuration emphasizes surface reactions without omitting the effect of any eventual gas-phase reactions. This investigation allowed the calculation of the overall activation energy from the temperature-dependent consumption trend of the precursor as well as the activation energies of the involved paths from the trend of the corresponding products. The decomposition of trimethylgallium shows the production of unsaturated hydrocarbons that are considered as a source of contamination, whereas tris(tert-butyl)gallium and triethylantimony undergo clean but multipath decomposition mechanism, for which the occurrence temperature ranges were determined.

\section{Acknowledgments}

The authors gratefully acknowledge financial support by the Deutsche Forschungsgemeinschaft in the context of the Priority Program (Schwerpunktprogramm) 1119. They are also grateful to Professor S. Schulz, University Essen-Duisburg, for the kind supply of the precursors.

\section{References}

1. Khostikov, V. P.; Khvostikova, O. A.; Gazaryan, P. Y.; Sorokina, S. V.; Potapovich, N. S.; Malevskaya, A. V.; Kaluzhniy, N. A.; Shvarts, M. Z. Andreev, V. M. Photovoltaic Cells Based on GaSb and Ge for Solar and
Thermophotovoltaic Applications. Transactions of the ASME J. Solar Energy Eng. 2007, 129(3), 291-297.

2. Basu, S.; Chen, Y. B.; Zhang, Z. M. Microscale Radiation in Thermophotovoltaic Devices-A Review. Int. J. Energy Res. 2007, 31(6/7), 689-716.

3. Bennett, B. R.; Magno, R.; Boos, J. B.; Kruppa, W.; Ancona, M. G. Antimonide-Based Compound Semiconductors for Electronic Devices: A Review. Solid-State Electronics 2005, 49(12), 1875-1895.

4. Danilova, T. N.; Zhurtanov, B. E.; Imenkov, A. N.; Yakovlev, Y. P. Light-Emitting Diodes Based on GaSb Alloys for the 1.6-4.4 $\mu \mathrm{m}$ Mid-Infrared Spectral Range. Semiconductors 2005, 39(11), 1235-1266.

5. Razeghi, M. Overview of Antimonide Based III-V Semiconductor Epitaxial Layers and Their Applications at the Center for Quantum Devices. Eur. Phys. J. Appl. Phys. 2003, 23(3), 149-205.

6. Biefeld, R. M. The Metalorganic Chemical Vapor Deposition and Properties of III-V Antimony-Based Semiconductor Materials. Mater. Sci. Eng. R Reports 2002, 36(4), 105-142.

7. Wang, C. A. Progress and Continuing Challenges in GaSb-Based III-V Alloys and Heterostructures Grown by Organometallic Vapor-Phase Epitaxy. J. Crystal Growth 2004, 272(1/4), 664-681.

8. Creighton, J. R.; Lykke, K. R.; Shamamian, V. A.; Kay, B. D. Decomposition of Trimethylgallium on the Gallium-Rich GaAs(100) SurfaceImplications for Atomic Layer Epitaxy. Appl. Phys. Lett. 1990, 57(3), $279-281$.

9. McCaulley, J. A.; Shul, R. J.; Donnelly, V. M. Kinetics of Thermal Decomposition of Triethylgallium, Trimethylgallium, and Trimethylindium Adsorbed on GaAs(100). J. Vac. Sci. Technol. A Vac. Surf. Films 1991, 9(6), 2872-2886

10. Wong, K. C.; McBurnett, B. G.; Culp, R. D.; Cowley, A. H.; Ekerdt, J. G. Homolysis Versus $\beta$-Hydride Elimination in the Decomposition of Trialkylgallium on GaAs(100). Surf. Sci. 1998, 416(3), 480-487.

11. Flores, C. R.; Zhou, X. L.; White, J. M. SSIMS Identification of Surface Intermediates in the Thermal Decomposition of TMGa on Si(100). Surf. Sci. 1992, 261(1/3), 99-110.

12. Aquino, A. A.; Jones, T. S. A Comparative Study of the Adsorption and Thermal Decomposition of Triethylgallium and Trimethylgallium at GaAs(100) Surfaces Studied by Electron Energy Loss Spectroscopy. Appl. Surf. Sci. 1996, 104, 304-311.

13. Lam, H. T.; Vohs, J. M. Surface Reactions of Trimethylgallium on MOVPE-Grown GaN(0001). Surf. Sci. 1999, 426(2), 199-211.

14. Buhaenko, D. S.; Patel, H.; Pemble, M. E. The Adsorption and Decomposition of Trimethylgallium at GaAs(100) Surfaces. J. Phys. Condens. Matter 1991, 3, S157-S160.

15. Pelzel, R. I.; Hopcus, A. B.; Owen, J. H. G.; Nosho, B. Z.; Weinberg W. H. Chemistry of $[(t$-butyl $) \mathrm{GaS}](4)$ on $\mathrm{Si}(100)-(2 \times 1)$. J. Vac. Sci. Technol. B 1998, 16(4), 2399-2403.

16. Heitzinger, J. M.; Ekerdt, J. G. Chemical Reactions of Triethylantimony on GaAs(100). J. Vac. Sci. Technol. A Vac. Surf. Films 1995, 13(6), 2772-2780.

17. Yong, K.; Ekerdt, J. G. Surface Reaction of Triethylgallium and Triethylantimony on $\mathrm{GaSb}(100)-(1 \times 3)$. Surf. Sci. 2000, 448(2/3), 108-116.

18. Wilson, J.; Guo, H.; Morales, R.; Podgornov, E.; Lee, I.; Zaera, F. Kinetic Measurements of Hydrocarbon Conversion Reactions on Model Metal Surfaces. Phys. Chem., Chem. Phys. 2007, 9(29), 3830-3852.

19. Chen, Q.; Dapkus, P. D. On the Thermal Decomposition of Trimethylgallium-A Molecular Beam Sampling Mass Spectrometry Study. J. Electrochem. Soc. 1991, 138(9), 2821-2826.

20. Lee, P. W.; Omstead, T. R.; McKenna, D. R.; Jensen, K. F. In Situ Mass Spectrometry and Thermogravimetric Studies of GaAs MOCVD GasPhase and Surface Reactions. J. Crystal Growth 1987, 85(1/2), 165-174.

21. Cui, J.; Ozeki, M.; Ohashi, M. Dynamic Approach to the Surface Reaction of Tri-isobutylgallium (TIBGa) on GaAs(001) by Using Molecular Beam Scattering. J. Crystal Growth 1998, 188(1/4), 137-143.

22. Schafer, J.; Simons, A.; Wolfrum, J.; Fischer, R. A. Detection of GasPhase Species in MOCVD of GaN Using Molecular Beam Quadrupole Mass Spectrometry. Chem. Phys. Lett. 2000, 319(5/6), 477-481.

23. Creighton, J. R.; Wang, G. T. Reversible Adduct Formation of Trimethylgallium and Trimethylindium with Ammonia. J. Phys. Chem. A 2005 109(1), 133-137.

24. Bergmann, U.; Reimer, V.; Atakan, B. An Experimental Study of the Reactions of Trimethylgallium with Ammonia and Water Over a Wide Temperature Range. Phys. Chem., Chem. Phys. 1999, 1(24), 5593-5599.

25. Schmid, R.; Basting, D. Gas Phase Chemistry in Gallium Nitride CVD: Theoretical Determination of the Arrhenius Parameters for the First Ga-C Bond Homolysis of Trimethylgallium. J. Phys. Chem. A 2005, 109(11), 2623-2630.

26. Allendorf, M. D.; Melius, C. F.; Bauschlicher, C. W. Heats of Formation and Bond Energies in Group III Compounds. J Physique IV (France) 1999, 9(P8), 23-31.

27. Jacko, M. G.; Price, S. J. W. Pyrolysis of Trimethyl Gallium. Can. J. Chem. (Revue Canadienne De Chimie) 1963, 41(6),1560.

28. Park, C.; Kim, J. H.; Yoon, D.; Han, S.; Doh, C.; Yeo, S.; Lee, K. H.; Anderson, T. J. Identification of a Gallium-Containing Carbon Deposit Produced by Decomposition of Trimethyl gallium. J. Electrochem. Soc. 2005, 152(5), C298-C303.

29. Cowley, A. R.; Downs, A. J.; Marchant, S.; Macrae, V. A.; Taylor, R. A Crystal Structures of Tris(tert-Butyl)Boron, -Aluminum,-Gallium, and -Indium: Nonplanarity of the AlC3 Skeleton and Evidence of Inter- and Intramolecular "Agostic" or Hyperconjugative Interactions. Organometallics 2005, 24(23), 5702-5709. 
30. Hopcus, A. B.; Yi, S. I.; Chung, C. H.; Pelzel, R. I.; Weinberg, W. H. Growth of GaS on GaAs(100)- $(4 \times 2)$ with the Single-Source Precursor [(Bu-t)GaS](4). Surf. Sci. 2000, 446(1/2), 55-62.

31. Schulz, S.; Fahrenholz, S.; Schuchmann, D.; Kuczkowski, A.; Assenmacher, W.; Reilmann, F.; Bahlawane, N.; Kohse-Hoinghaus, K. Single Source Precursor-Based HV-MOCVD Deposition of Binary Group 13 Antimonide Thin Films. Surf. Coat. Technol. 2007, 201(22/23), 9071-9075.

32. Schulz, S.; Nieger, M. Synthesis and Structural Characterization of the First Completely Alkyl-Substituted Ga-Sb Lewis Acid-Base Adducts. J. Chem. Soc. Dalton Trans. 2000, (5), 639-642.

33. Tsang, W. Thermal Decomposition of Some tert-Butyl Compounds at Elevated Temperatures. J. Chem. Phys. 1964, 40(6), 1498-1505.

34. Gimmnich, P.; Greiling, A.; Lorberth, J.; Thalmann, C.; Rademann, K.; Zimmermann, G.; Protzmann, H.; Stolz, W.; Gobel, E. O. New Alternative Arsenic Precursors for the Metal Organic Vapor-Phase Epitaxy of III-V semiconductors in Situ Formation of As-H Functionality by $\beta$
Elimination of Specific Metal Organic Arsenic Compounds. Mater. Sci. Eng. B Solid State Mater. Adv. Technol. 1993, 17(1/3), 21-24.

35. Zhang, Y.; Cleaver, W. M.; Stuke, M.; Barron, A. R. UV Excimer Laser Photochemistry of Hybrid Organometallic Compounds of Gallium. Appl. Phys. A Mater. Sci. Processing 1992, 55(3), 261-268.

36. Boero, M.; Morikawa, Y.; Terakura, K.; Ozeki, M. First Principles Study of Thermal Decomposition of Alkylgallium and Tertiary Butylarsine. J. Chem. Phys. 2000, 112(21), 9549-9556.

37. Pickett, N. L.; Foster, D. F.; Maung, N.; Cole-Hamilton, D. J. Studies of the Thermal and Photochemical Decomposition Mechanisms of $\left(\mathrm{Bu}_{2} \mathrm{Se}\right)$ Se-t in the Presence or Absence of Analogues. J. Mater. Chem. 1999, 9(12), 3005-3014.

38. Skulan, A. J.; Nielsen, I. M. B.; Melius, C. F.; Allendorf, M. D BAC-MP4 Predictions of Thermochemistry for Gas-Phase Antimony Compounds in the Sb-H-C-O-Cl System. J. Phys. Chem. A 2006, 110(17), 5919-5928. 